\title{
COMPARISON OF ARTHROSCOPIC ASSISTED REDUCTION AND INTERNAL FIXATION VERSUS OPEN REDUCTION AND INTERNAL FIXATION IN TIBIAL PLATEAU FRACTURE TREATMENT
}

\author{
Ranadip Halder'1, Soumyadip Dutta², Shouvik Saha3, Dilip Kumar Pal ${ }^{4}$, Debojyoti Mukherjee ${ }^{5}$, Swapan Mondal ${ }^{6}$ \\ ${ }_{1}^{1}$ Postgraduate Trainee, Department of Orthopaedics, R. G. Kar Medical College and Hospital, Kolkata. \\ ${ }^{2}$ Assistant Professor, Department of Orthopaedics, R. G. Kar Medical College and Hospital, Kolkata. \\ ${ }^{3}$ Postgraduate Trainee, Department of Orthopaedics, R. G. Kar Medical College and Hospital, Kolkata. \\ 4 Professor and HOD, Department of Orthopaedics, R. G. Kar Medical College and Hospital, Kolkata. \\ ${ }^{5}$ Assistant Professor, Department of Orthopaedics, R. G. Kar Medical College and Hospital, Kolkata. \\ ${ }^{6}$ Postgraduate Trainee, Department of Orthopaedics, R. G. Kar Medical College and Hospital, Kolkata.
}

ABSTRACT

\section{BACKGROUND}

Tibial plateau fractures are challenging. Arthroscopy allows evaluation of articular fracture reduction better. We evaluated functional and radiological outcomes of treatments for tibial plateau fractures -arthroscopic assisted reduction and internal fixation (ARIF) and open reduction and internal fixation (ORIF).

\section{MATERIALS AND METHODS}

Total 30 patients, divided into group A and B. We included patients with i. Age $<65$ years, ii. Schatzker types I to IV fractures, iii. healthy skin, iv. >= $3 \mathrm{~mm}$ articular step off and excluded i. extensive articular communication, ii. open fractures, iii. Schatzker types V, VI. iv. Fractures $>3$ weeks. Group A treated by ARIF, group B by ORIF. Arthroscopic examination done at the beginning of operation. Reduction of fracture was checked with C-arm. 8 meniscal tears- partially excised in 6 patients. No significant differences in gender, age, and fracture types between groups $(\mathrm{P}>0.05)$. Last follow-up evaluation included range of motion, Modified Rasmussen radiographic and clinical scores, Ahlback radiologic scale score for osteoarthritis.

\section{RESULTS}

All achieved union. In group A, the mean modified Rasmussen clinical score was 27.93 \pm 1.67 (range 24-30), while in group B 25.53 \pm 2.92 (Range 21-30). According to modified Rasmussen radiological results, the mean score for group A was is $8.60 \pm 1.35$ (Range 6-10), while in group B 6.73 \pm 1.03 (Range 5-8). Independent Samples T test was used for statistical analysis. Hardware removed in 4 patients due to prominence.

\section{CONCLUSION}

ARIF can be alternative treatment for tibial plateau fractures, with good results and less complications. ARIF may improve clinical outcome in Schatzker types II to IV fractures.

\section{KEYWORDS}

Arthroscopic Assisted, Tibial Plateau, Osteoarthritis.

HOW TO CITE THIS ARTICLE: Halder R, Dutta S, Saha S, et al. Comparison of arthroscopic assisted reduction and internal fixation versus open reduction and internal fixation in tibial plateau fracture treatment. J. Evolution Med. Dent. Sci. 2017;6(11):815-820, DOI: $10.14260 / \mathrm{Jemds} / 2017 / 178$

\section{BACKGROUND}

Tibial Plateau Fractures are very serious challenging fractures. Results of the treatment depend mainly on articular fracture reduction and associated soft tissue injuries. ${ }^{1-4}$ preoperatively, plain radiographs and CT scans are used to evaluate displacement of the fracture. During reduction, evaluation of the articulating surface of the tibia is essential. Ligamentous stability and preservation of the menisci are important for a longstanding result.5,6 Open reduction and internal fixation has a significant complication rate 7,8 Which has encouraged interest in percutaneous techniques 9,10

Financial or Other, Competing Interest: None.

Submission 27-12-2016, Peer Review 18-01-2017,

Acceptance 27-01-2017, Published 06-02-2017.

Corresponding Author:

Dr. Ranadip Halder,

Tili Para Road, Nandi Para,

P.O.+P. S. Nabadwip,

Dist-Nadia-741302,

West Bengal.

E-mail: rndp.halder4@gmail.com

DOI: $10.14260 /$ jemds $/ 2017 / 178$
Arthroscopy is particularly helpful since it provides a good view of the fractured articular surface and any other intra-articular lesion, while limiting soft-tissue damage. Good early results of arthroscopically-assisted osteosynthesis of fractures of the tibial plateau have been reported previously.

\section{MATERIALS AND METHODS}

We performed arthroscopically-assisted treatment in 15 patients with fracture of the proximal tibia involving the knee and 15 patients with open method. We included the patients with-

i. Age $<65$ years,

ii. Schatzker types I to IV fractures,

iii. Healthy skin,

iv. >= $3 \mathrm{~mm}$ articular step off and excluded-

i. Extensive articular communication,

ii. Open fractures,

iii.Schatzker types V, VI.

iv. Fractures $>3$ weeks. 


\begin{tabular}{|c|c|c|c|c|c|c|}
\hline Case & Age & $\mathbf{M} / \mathbf{F}$ & Mechanism of Injury & Schatzker Type & Associated Lesions & Treatment of Lesions \\
\hline 1 & 36 & Male & RTA & I & Meniscal Tear & Partial Menisectomy \\
\hline 2 & 55 & Female & RTA & II & Meniscal Tear & Partial Menisectomy \\
\hline 3 & 42 & Male & RTA & II & Meniscal Tear & Partial Menisectomy \\
\hline 4 & 46 & Female & RTA & I & Meniscal Tear & Partial Menisectomy \\
\hline 5 & 32 & Male & RTA & II & - & - \\
\hline 6 & 34 & Male & RTA & I & - & - \\
\hline 7 & 35 & Male & RTA & II & - & - \\
\hline 8 & 35 & Male & RTA & III & - & - \\
\hline 9 & 46 & Female & Fall & IV & Meniscal Tear & Debridement \\
\hline 10 & 45 & Male & Fall & IV & ACL Tear & Reconstruction \\
\hline 11 & 40 & Female & Fall & III & $\mathrm{ACL}+\mathrm{MCL}$ & Reconstruction \\
\hline 12 & 36 & Male & Playing & II & ACL Tear & Conservative \\
\hline 13 & 55 & Female & Fall & II & - & - \\
\hline 14 & 42 & Female & RTA & I & Meniscal Tear & Partial Menisectomy \\
\hline 15 & 46 & Female & RTA & IV & Meniscal Tear & Partial Menisectomy \\
\hline 16 & 29 & Male & RTA & III & Meniscal Tear & Debridement \\
\hline 17 & 34 & Female & RTA & III & ACL Tear & Conservative \\
\hline 18 & 43 & Male & RTA & IV & ACL Tear & Reconstruction \\
\hline 19 & 38 & Male & RTA & II & - & - \\
\hline 20 & 40 & Female & RTA & I & - & - \\
\hline 21 & 48 & Male & Fall & I & - & - \\
\hline 22 & 42 & Female & RTA & II & Meniscal Tear & Partial Menisectomy \\
\hline 23 & 44 & Male & RTA & IV & MCL & Conservative \\
\hline 24 & 40 & Male & RTA & III & - & - \\
\hline 25 & 43 & Female & RTA & IV & Meniscal Tear & Debridement \\
\hline 26 & 33 & Male & RTA & III & - & - \\
\hline 27 & 35 & Female & Playing & I & Meniscal Tear & Conservative \\
\hline 28 & 46 & Male & Plaving & I & - & - \\
\hline 29 & 52 & Female & RTA & III & Meniscal Tear & Conservative \\
\hline 30 & 40 & Male & RTA & IV & ACL Tear & Conservative \\
\hline \multicolumn{7}{|c|}{ Table 1. Details of patients profile, mechanism of injury, associated lesions \& treatment } \\
\hline
\end{tabular}

We divided the patients into 2 groups. Group A was treated with arthroscopic assisted (ARIF) and Group B was treated with open reduction method. 4 patients lost in follow up. There were 17 men and 13 women with a mean follow-up time of 12 months ( 8 to 18 months). Three fractures were the result of sporting accidents and twenty two of a road traffic accident (R.T.A.); five fractures were the result of a fall from a height. (Table I).

Preoperatively, all patients were assessed clinically and with plain radiographs and CT scanning. Fractures were evaluated using the Schatzker classification (Table II). ${ }^{11,12}$

\begin{tabular}{|c|c|}
\hline I & Pure Split \\
\hline II & Split with Depression \\
\hline III & Pure Deprerssion \\
\hline IV & Medial Condyle Fracture \\
\hline & Table II. Schatzker classification \\
\hline
\end{tabular}

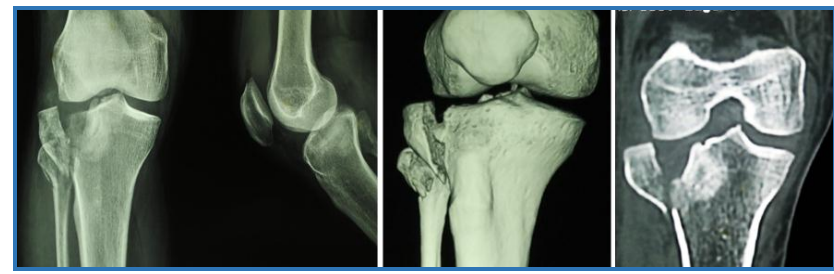

Picture. 1, 2, 3. Pre-operative x-ray and CT scan

\section{Surgical Technique}

All patients were placed in the supine position, with the affected leg in hanging from side of the table. Before starting the operation standard portals for knee arthroscopy done. Anteromedial and anterolateral parapatellar portals made. Thorough lavage given, evacuation of the joint done, loose bodies removed and the fracture pattern seen through arthroscope.
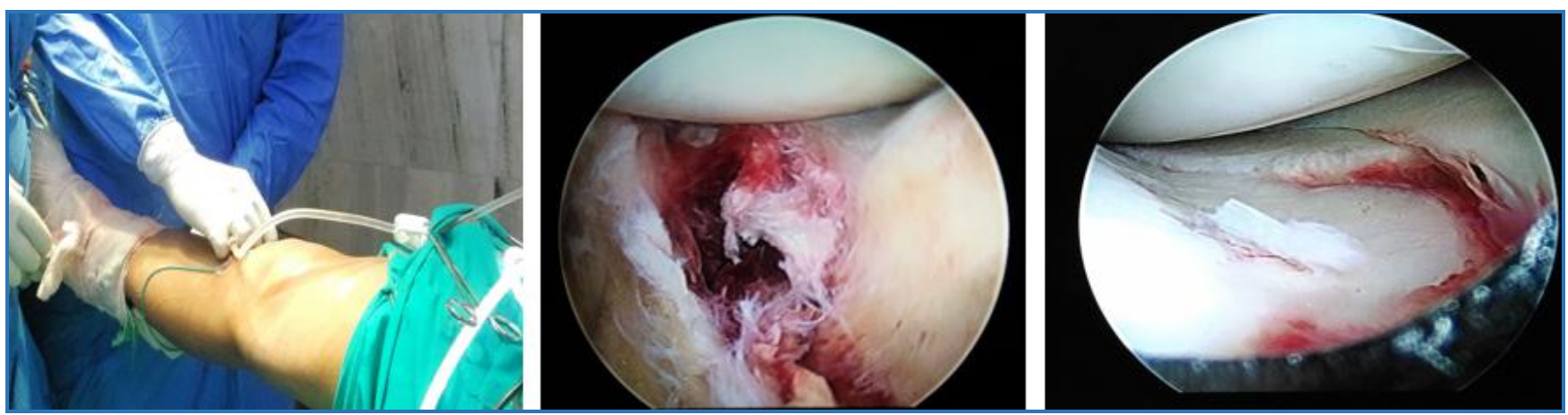

Pictures 4 a,b,c. Showing the making of portals for knee arthroscopy and the articular step off during the procedure 
All the cases done under spinal anaesthesia though 4 out of 33 patients had to convert to general anaesthesia because of intraoperative some complications. Before starting the arthroscopy the fluoroscopic machine was positioned according to the pattern of fractures. During arthroscopy the contineuous irrigation fluid given to drain hematoma, loose bodies and to see the articular congruity better and monitored carefully to avoid compartment syndrome. All the cases done under tourniquet. Meniscal probing done to examine the continuity and where required partial menisectomy done. 4 patients found to have ACL tear but they were not addressed at that time. After completing the arthroscopic examination the fracture reduction tried according to schatzker classification and our inclusion criterias.

For type I fractures wherte only split fractures there percutaneously $6.5 \mathrm{~mm}$ cancellous csrews with washer used as a rafting. The fractured part elevated with use of $\mathrm{k}$ wire or bone impactor as a joystick to reduce the fracture in position and then checked under fluoroscopy and then screw given. For type II fractures same technique used and where required buttress plate used. For type III the same procedure used and the void filling done by iliac crest bone graft or artificial bone graft substitutes for both type II and III. For type IV the antero medial or postero medial antiglide plating done (bone grafted where required).

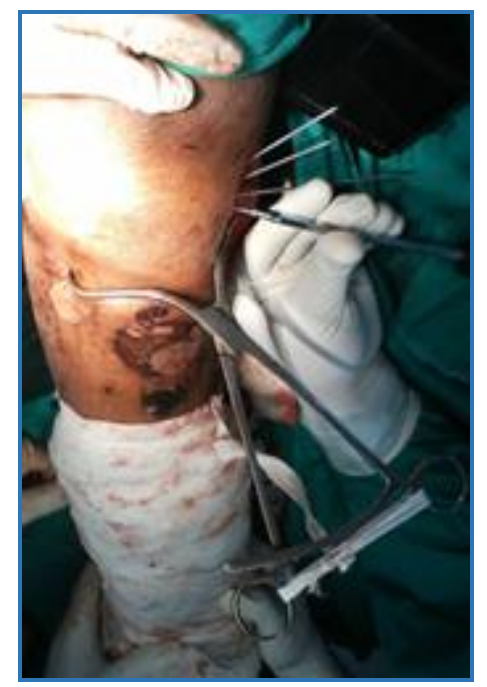

Picture 4d. reduction of fracture with reduction clamp and $k$ wires

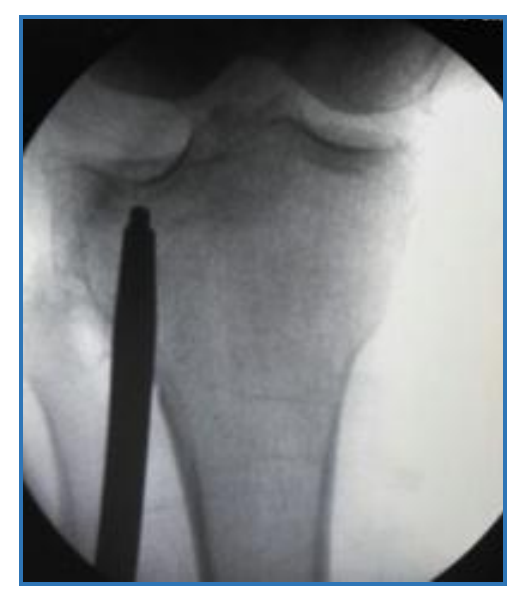

Picture 4e. elevation of the split and depressed part

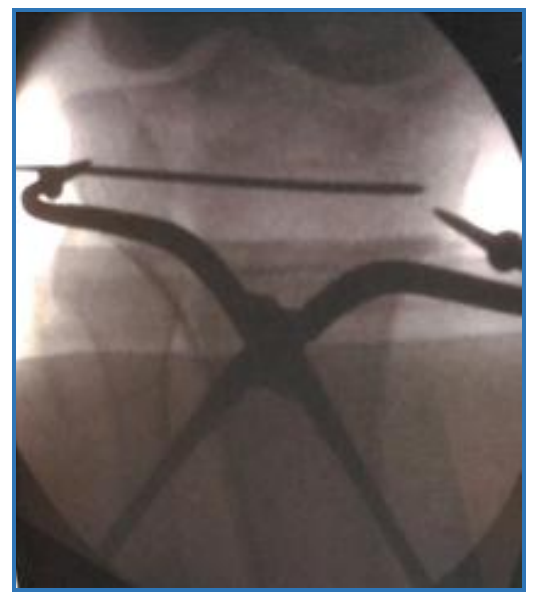

Picture 4f. provisional fixation

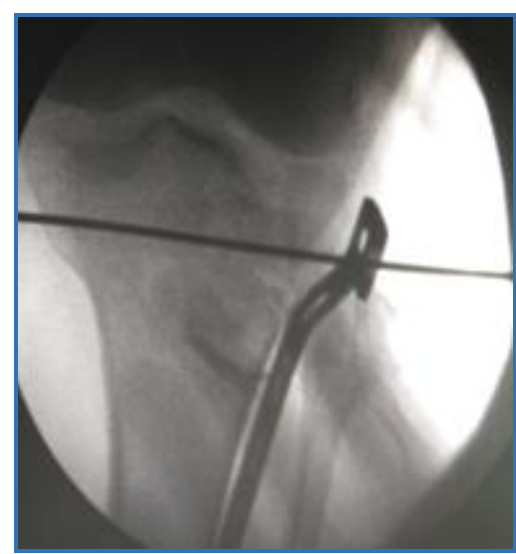

Picture 4g. percutaneuous cancellous screws (6.5 $\mathrm{mm})$

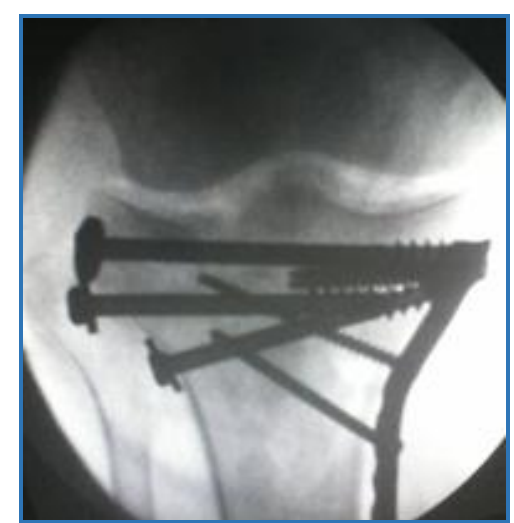

Picture 4h. Plating in anterolateral aspect

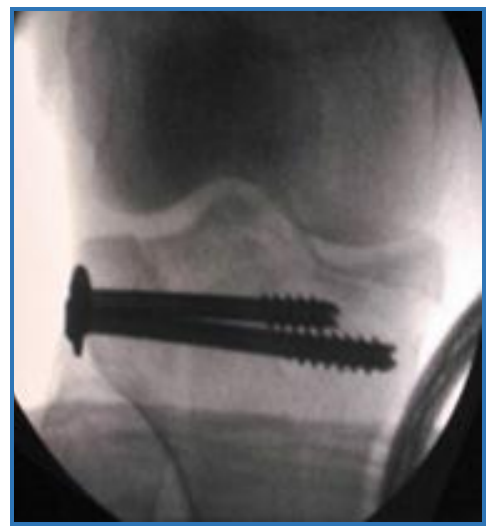

Picture 4i. Plating in anteromedial aspect 


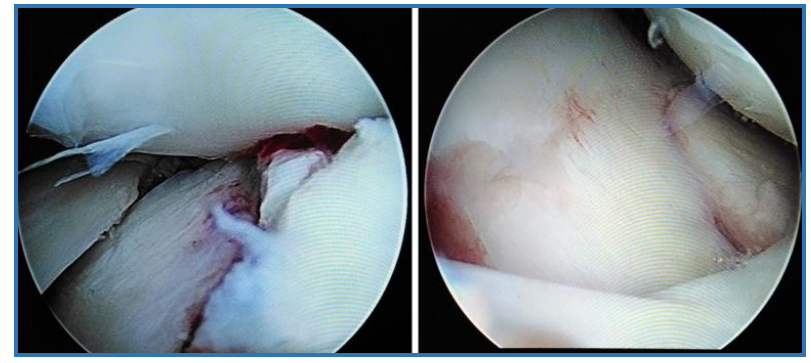

Picture $4 j$ \& $k$. showing arthroscopic view after reduction and fixation of the fractures

After reduction and fixation of the fractures we had checked again by arthroscopically for articular reduction and accepted if that was $<=2 \mathrm{~mm}$.

Bone grafting was carried out in eight of the fractures reviewed and in two not available for follow-up. . The mean time for anaesthesia was 90 minutes ( 45 to 210 ). All patients were mobilised immediately after surgery, using continuous passive motion. Weight-bearing was delayed until there was radiological evidence of healing of the fracture, generally at about eight weeks. Patients were assessed clinically using the rasmussens clinical and radiological scores. Osteoarthritic changes were judged according to the scale of Ahlbäck and the mechanical axis was measured on the radiographs.

\section{RESULTS}

In group A, the average Modified Rasmussen clinical score is $27.93 \pm 1.67$ (range 24-30). Scores related to each Schatzker type of fractures are reported in Table 2 . The following scores were obtained: 28, 28, 29.25 and 26, respectively, for Schatzker I, II, III and IV types of fracture. In group B, the average Rasmussen clinical score is $25.53 \pm 2.92$ (range 21$30)$. Analysing the clinical scores for each type of fracture, 28.6, 26.67, 24.33 and 21.75 were obtained, respectively, for Schatzker I, II, III and IV types.

According to Modified Rasmussen radiological results, the average score for group A is $8.60 \pm 1.35$ (Range 6-10). The scores for each type of fracture were, 9.67, 8.80, 7.0, 9.33 respectively, for Schatzker I, II, III and IV types. In group B, the average score was $6.73 \pm 1.03$ (Range 5-8). The scores for each type of fracture were 7.0, 5.67, 7.33 and 6.75 respectively, for Schatzker I, II, III and IV types.

According to Modified Rasmussen clinical score all 8 patients from group A (Schatzker type I \& II) have excellent results, whether from group B 5 have excellent results and 3 have good results (Schatzker type II). From the rest 7 patients from group A 4 patients have excellent results (3 from Schatzker type III \& 1 from Schatzker type IV). From group B 3 have good results (Schatzker type III) and 4 have fair results (Schatzker type IV).

There were no complications directly associated with arthroscopic procedures in group A. 4 patients in group B and 1 patient from group $A$ had a superficial infection treated with antibiotic therapy after sample culture and identification of bacteria. There were no postoperative incidences of compartment syndrome in either group.

Regarding the intraarticular lesion there were 12 patients who had partial meniscus tear (7 lateral and 5 medial meniscus). Excision of the fragment and menicsal balancing done in those patients in same sitting. 5 patients from had partial ACL tear and 1 had full tear. 2 patients had partial
MCL tear. ACL tears were reconstructed later after fracture healing. Partial weight bearing allowed within 6 weeks and full weight bearing within 12 weeks maximum. We followed up the patients in 2 weeks. 6 weeks, 3 months, 6 months, 12 months and 18 months.

All patients achieved union. However, we removed implant from 6 patients due to prominence. There were no mechanical failure. Post-operative pain management better in ARIF group. Upto 130 degree knee flexion possible in ARIF group within 9 months but upto 120 degree possible in ORIF group sat that time. After 1 year 4 patients had symptoms of arthritis which were graded according to Ahlback radiologic scale score for osteoarthritis.

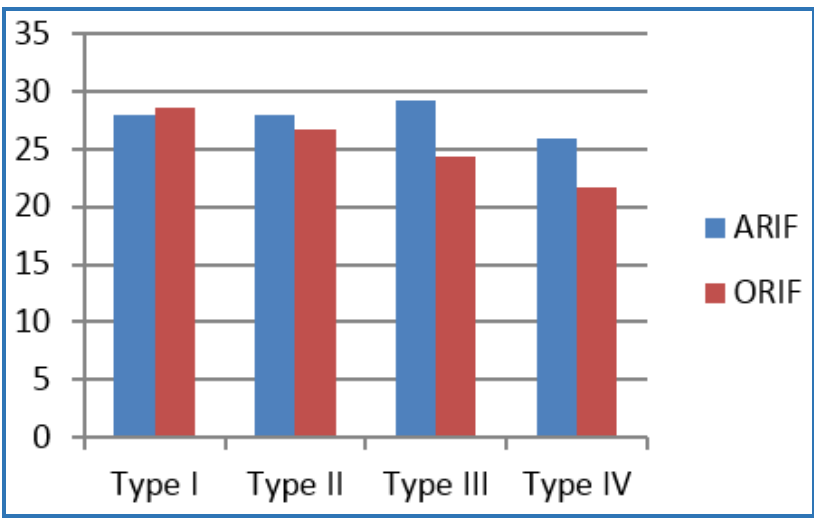

Graph 1. Comparison of mean values of modified rasmussen clinical score in two groups

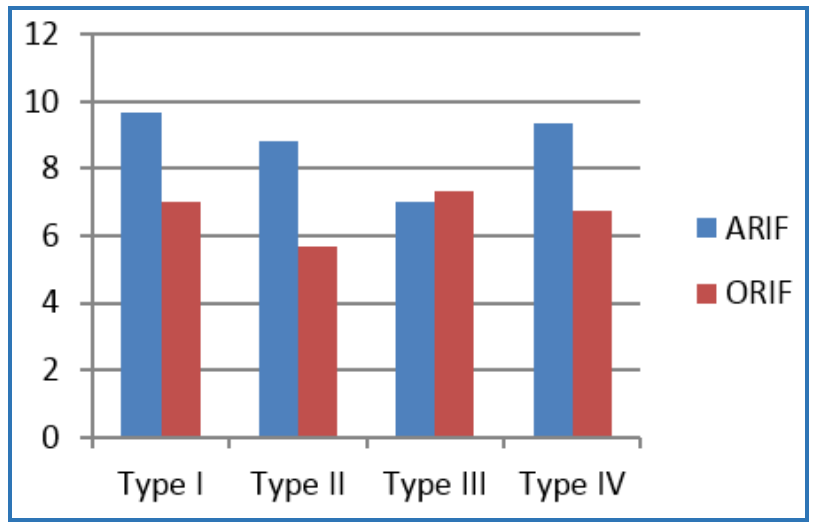

Graph 2. Comparison of mean values of modified rasmussen radiological score in two groups

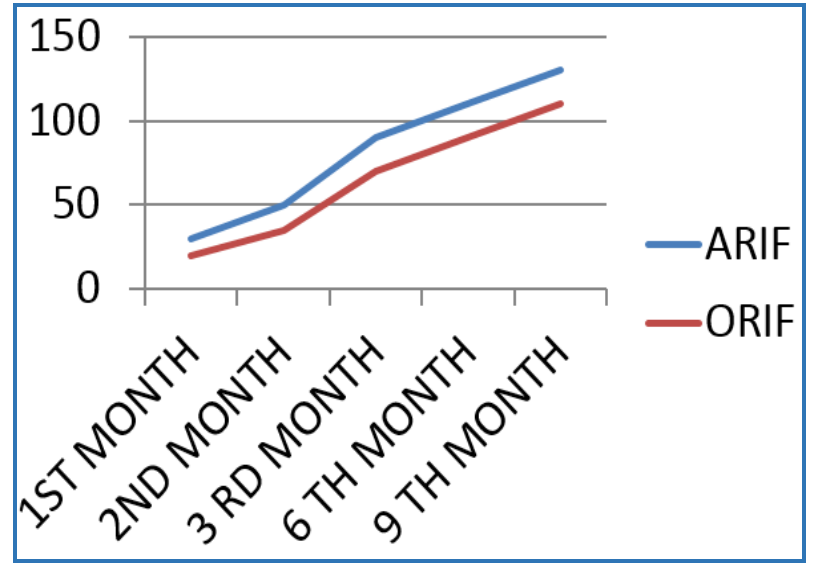

Graph 3. Progression of range of motion during post-operative follow up in two groups and it shows better outcome in ARIF group 


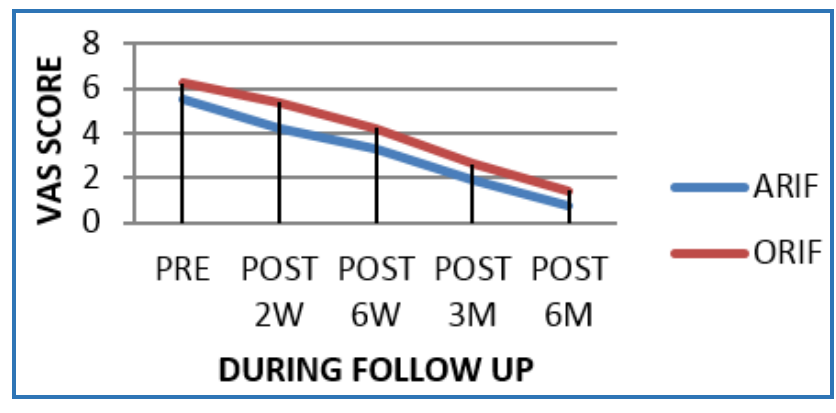

Graph 4. Pre op and post-operative VAS score showing better result in group ARIF

\section{DISCUSSION}

Tibial plateau fractures always require anatomical reduction and stable fixation in order to begin mobilisation early. And also to avoid knee instability later the ligaments pathology should be addressed in proper way.

Arthroscopic procedures used in the treatment of certain types of tibial plateau fractures have good results. ${ }^{13-18}$ Type I fractures had excellent results in both groups. There was no posttraumatic sequel from either approach. Schatzker II fractures, were associated often with a lateral meniscus lesion and an MCL or ACL lesion. Excellent results were obtained in group A and 3 patients from group B had good results. With the ARIF technique, it was possible to check and treat the associated injuries. We observed that patients treated by ARIF technique showed better values of ROM and sustained less pain than patients of group B, particularly within 12 months after surgery. Both these are clinically and statistically significant also.

In type III fractures treated by ARIF and ORIF, excellent as well as good results were obtained in both groups. There was a high chance of lateral meniscus lesions, suggesting ARIF treatment may be better to identify and treat these problems as well as to restore of the articular congruity.

Schatzker IV type fractures treated by ARIF technique demonstrated better results than those treated by ORIF. This may be due to we could avoid arthrotomy in ARIF procedure. This type of fractures were characterized by many associated injures (Medial meniscus tears, ACL and MCL tear). In ARIF group, the meniscal lesions were treated after the reduction and fixation of the fracture, whereas the ACL was mainly treated conservatively and one ACL was reconstructed after fracture union.

Knee arthroscopy is very helpful in the detection and treatment of associated intra-articular lesions. The reported incidence of meniscal lesions associated with tibial plateau fractures ranges from $14 \%$ to $50 \% .{ }^{19-20}$ There seems to be no apparent correlation with a specific fracture type. ${ }^{21}$ Cruciate ligament injuries are reported in between 5\% and 32\% of cases. ${ }^{19-20}$ Associated soft tissue injuries are found in between $23 \%$ and $56 \%{ }^{19}$ Overall intra-articular injuries are reported up to $53.8 \% .22$ We found soft tissue lesions in $20 \%$ of the patients in our series. Twelve patients had a meniscus lesion $(40 \%)$ and six patients $(20 \%)$ had an anterior cruciate ligament injury. One patient sustained a combined, complete rupture of the anterior cruciate and medial collateral ligament.
Cassard et al described 26 patients with Schatzker types I-IV fractures treated arthroscopically and concluded that the results were as good as or better than from ORIF. 23

Barei et al has reported an $8.4 \%$ deep infection rate; the Canadian Orthopaedic Trauma Society reported $17 \% .{ }^{24,25}$ In our case series the infection rate was 5 out of 30 patients $(16.6 \%)$. In between them 3 were superficial and 2 were deep. We removed hardware from 4 patients after 1 year due to prominence.

\section{CONCLUSION}

There were no significant differences between ARIF and ORIF treatment for type I tibial plateau fractures. We found ARIF treatment preferable when we suspected meniscal tears were present during clinical examination after anaesthesia as it gave opportunity for simultaneous treatment. In cases of Schatzker II, III and IV fractures, there was a difference in outcomes in favour of ARIF and statistically significant. ARIF treatment was limited to less comminuted fractures and showed less incidence of infection and complications.

\section{REFERENCES}

[1] Blokker CP, Rorabeck CH, Bourne RB. Tibial plateau fractures. An analysis of results of treatment in 60 patients. Clin Orthop Relat Res 1984;182:193-9.

[2] Honkonen SE. Degenerative arthritis after tibial plateau fractures. J Orthop Trauma 1995;9(4):273-7.

[3] Schatzker J, McBroom R, Bruce D. The tibial plateau fracture. The toronto experience 1968-1975. Clin Orthop Relat Res 1979;138:94-104.

[4] Rasmussen PS. Tibial condylar fractures. Impairment of knee joint stability as an indication for surgical treatment. J Bone Joint Surg Am 1973;55(7):1331-50.

[5] Waddell JP, Johnston DW, Neidre A. Fractures of the tibial plateau: a review of 95 patients and comparison of treatment methods. J Trauma 1981;21(5):376-81.

[6] Hohl M. Managing the challenge of tibial plateau fractures. J Musculoskel Med 1991;8:70-86.

[7] Young MJ, Barrack RL. Complications of internal fixation of tibial plateau fractures. Orthop Rev 1994;23(2):149-54.

[8] Moore TM, Patzakis MJ, Harvey JP. Tibial plateau fractures: definition, demographics, treatment rationale, and long-term results of closed traction management or operative reduction. J Orthop Trauma 1987;1(2):97-119.

[9] Harper MC, Henstorf JE, Vessely MB, et al. Closed reduction and percutaneous stabilization of tibial plateau fractures. Orthopedics 1995;18(7):623-6.

[10] Koval KJ, Sanders R, Borrelli J, et al. Indirect reduction and percutaneous screw fixation of displaced tibial plateau fractures. J Orthop Trauma 1992;6(3):340-6.

[11] Gill TJ, Moezzi DM, Oates KM, et al. Arthroscopic reduction and internal fixation of tibial plateau fractures in skiing. Clin Orthop Relat Res 2001;383:243-9.

[12] Guanche CA, Markman AW. Arthroscopic management of tibial plateau fractures. Arthroscopy 1993;9:467-71.

[13] Itokazu M, Matsunaga T. Arthroscopic restoration of depressed tibial plateau fractures using bone and hydroxyapatite grafts. Arthroscopy 1993;9(1):103-8. 
[14] Itokazu $M$, Matsunaga $T$, Ishii $M$, et al. Use of arthroscopy and interporous hydroxyapatite as a bone graft substitute in tibial plateau fractures. Arch Orthop Trauma Surg 1996;115(1):45-8.

[15] Jennings JE. Arthroscopic management of tibial plateau fractures. Arthroscopy 1985;1(3):160-8.

[16] Keogh P, Kelly C, Cashman WF, et al. Percutaneous screw fixation of tibial plateau fractures. Injury 1992;23(6):387-9.

[17] Kiefer H, Zivaljevic N, Imbriglia JE. Arthroscopic reduction and internal fixation (ARIF) of lateral tibial plateau fractures. Knee Surg Sports Traumatol Arthrosc 2001;9(3):167-72.

[18] Wallenbock F, Ledinski C. Indications and limits of arthroscopic management of intra-articular fractures of the knee joint. Aktuelle Traumatol 1993;23(2):97101.

[19] Caspari RB, Hutton PM, Whipple TL, et al. The role of arthroscopy in the management of tibial plateau fractures. Arthroscopy 1985;1(2):76-82.

[20] Fowble CD, Zimmer JW, Schepsis AA. The role of arthroscopy in the assessment and treatment of tibial plateau fractures. Arthroscopy 1993;9(5):584-90.
[21] Vangsness CT, Ghaderi B, Hohl M, et al. Arthroscopy of meniscal injuries with tibial plateau fractures. J Bone Joint Surg 1994;76-B(3):488-90.

[22] Scheerlinck T, Ng CS, Handelberg F, et al. Mediumterm results of percutaneous, arthroscopically assisted osteosynthesis of fractures of the tibial plateau. J Bone Joint Surg Br 1998;80(6):959-64.

[23] Cassard X, Beaufils P, Blin JL, et al. Osteosynthesis under arthroscopic control of separated tibial plateau fractures. 26 case reports. Rev Chir Orthop Reparatrice Appar Mot 1999;85(3):257-66.

[24] Canadian Orthopaedic Trauma Society. Open reduction and internal fixation compared with circular fixator application for bicondylar tibial plateau fractures. Results of a multicenter, prospective, randomized clinical trial. J Bone Joint Surg Am 2006;88(12):2613-23.

[25] Barei DP, Nork SE, Mills WJ, et al. Complications associated with internal fixation of high energy bicondylar tibial plateau fractures utilizing a twoincision technique. J Orthop Trauma 2004;18(10):649-57. 